Supplement of Atmos. Chem. Phys. Discuss., 15, 5663-5712, 2015

http://www.atmos-chem-phys-discuss.net/15/5663/2015/

doi:10.5194/acpd-15-5663-2015-supplement

(C) Author(s) 2015. CC Attribution 3.0 License.

(c) (i)

\title{
Ultrafine particle sources and in-situ formation in a European megacity
}

M. Pikridas et al.

Correspondence to: S. N. Pandis (spyros@chemeng.upatras.gr) 


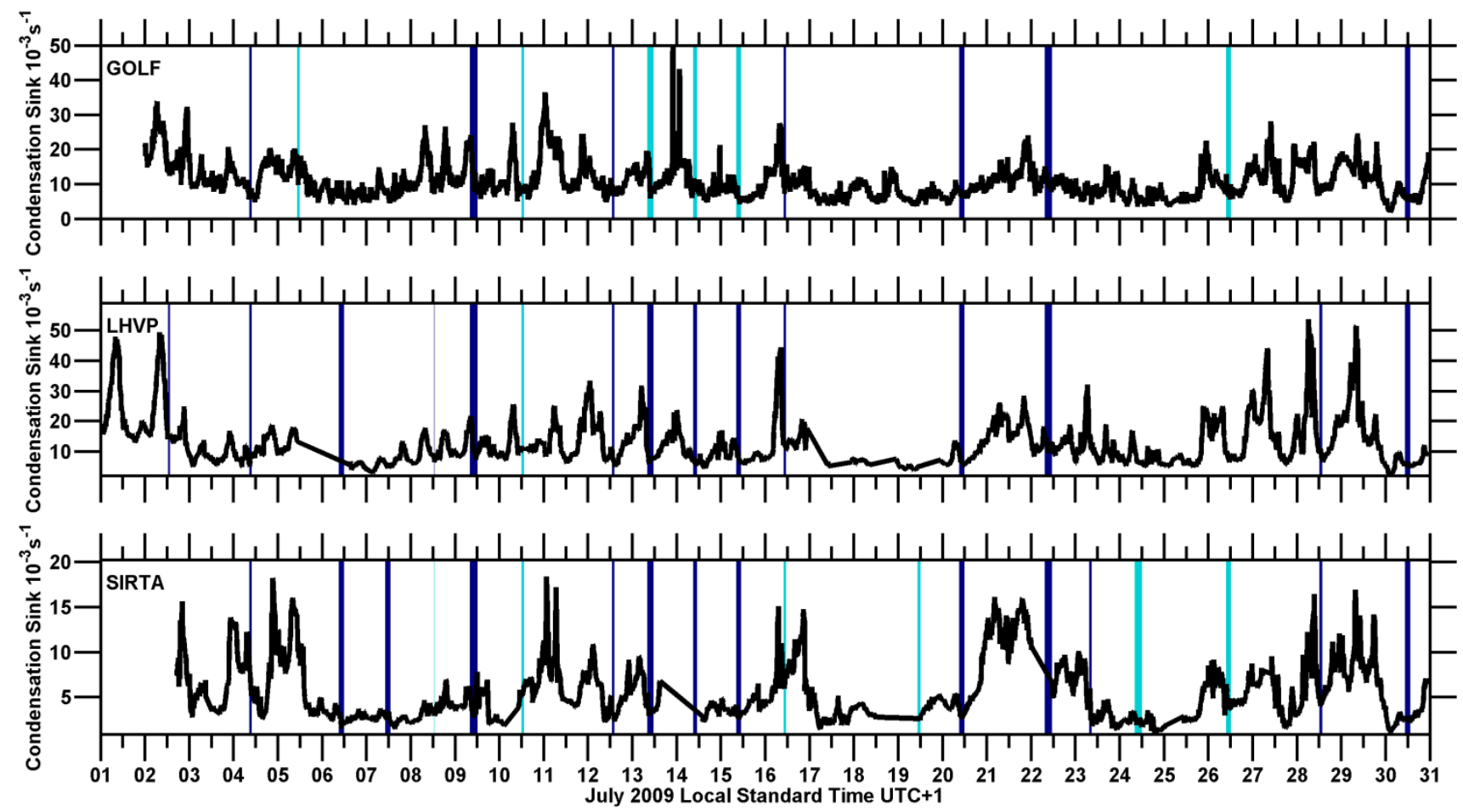

Fig. S1. Condensation sink measured at the three ground sites during July 2009. Dark and light blue bars indicate the event and undefined periods, respectively. 



Fig. S2. Number size distribution time series when a nucleation event was identified at SIRTA and/or LHVP but not at GOLF. $D_{\mathrm{p}}$ is the particle diameter. 


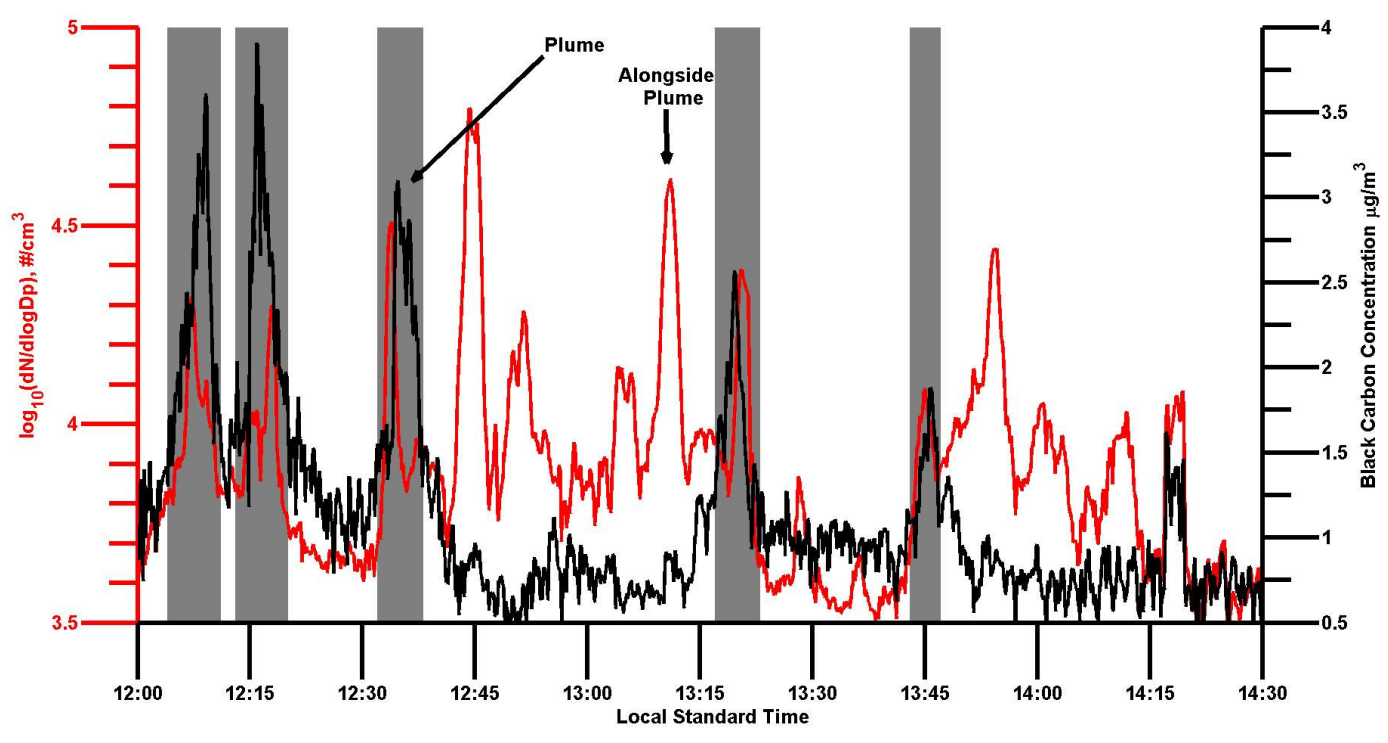

Fig. S3. Number (red line) and black carbon (black line) concentrations during airborne measurements on July $1^{\text {st }}$ 2009. Number concentration increases observed simultaneously with increases in black carbon mass concentration (grey areas) were attributed to the Paris plume. Number concentration increases were also observed along the plume. 

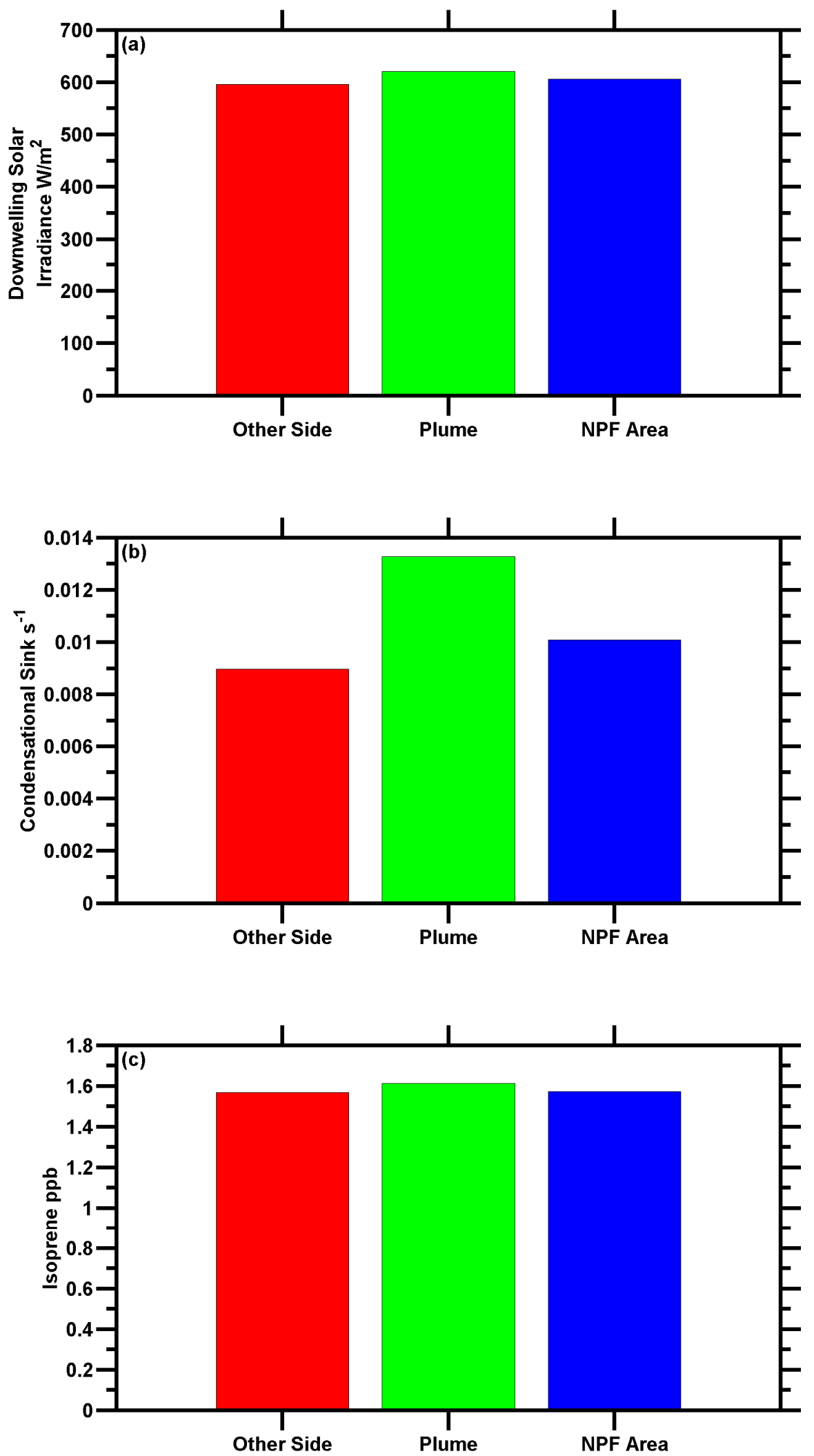

Fig. S4. Down welling solar irradiance (top), condensation sink (middle) and isoprene concentration (bottom) comparison of the Paris plume with areas on either side of the plume when high particle concentrations were observed at one side outside of the plume. Significant differences among these areas were not observed with respect to condensation sink, isoprene and solar irradiance. 